\title{
Determinants of tobacco use and perception, attitude about an antitobacco act in rural Haryana, North India
}

\section{Rakesh Kumar, Harshal Salve ${ }^{1}$, Puneet Misra ${ }^{1}$}

Indian Coalition for Control of lodine Deficiency Disorders, ${ }^{1}$ Centre for Community Medicine, All India Institute of Medical Sciences, New Delhi, India

Address for the Correspondence: Dr. Harshal Salve,

Old O. T. Block, Centre for Community Medicine, All India Institute of medical Sciences,

New Delhi - 110 029, India.

E-mail: harshalsalve@ymail.com

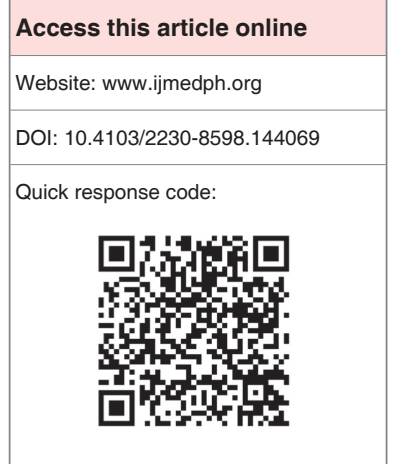

Background: Tobacco use is one of the most important preventable causes of morbidity and mortality in India. It is essential to study perception, practices and factors determining tobacco use to formulate the intervention for addressing this problem in the community. Materials and Methods: A cross-sectional study was carried out in 28 villages in Ballabgarh block of Faridabad, Haryana. This study aimed to understand factors determining tobacco use and to assess knowledge, attitude, practices about tobacco use and antitobacco act. Systematic random sampling was done to select study subjects. Total calculated sample size was 880 . One eligible male and one female were selected randomly from household. Knowledge was assessed using semi-structured interview schedule while attitude using five-point likert scale. In addition, focus group discussions and in-depth interviews were conducted among various stakeholders and opinion leaders to get insight about practices and factors determining tobacco use in the community. Results: Total 892 subjects were enrolled in the study, of which $51 \%$ were male. The mean age of the study subjects was 49.5 years (standard deviation: 17.5). Though awareness about harmful effects of tobacco use was reported, awareness about legislations under an antitobacco act was poor. Early initiation and continued use of all forms of tobacco were reported. Prevalent practice of tobacco use was attributed to pressure from peer groups, social customs and lack of de-addiction services at the community level by study subjects. Conclusion: Tobacco use in this rural community was mainly attributed to social and cultural factors. A multi-pronged public health approach is needed for addressing this complex problem the community.

Key words: Antitobacco act, determinants, perception and attitude, rural India, tobacco use

\section{INTRODUCTION}

Globally, tobacco use is one of the major preventable causes of morbidity and mortality. ${ }^{[1]}$ According to the World Health Organization, tobacco kills more than 5 million people in the world, which is more than the mortality due to tuberculosis, HIV/AIDS and malaria combined. In India, it is estimated that 1 million deaths occur due to tobacco every year. ${ }^{[1]}$ If left unchecked; the mortality due to tobacco consumption will rise to 1.5 million by $2020 .{ }^{[1]}$ Global Adult Tobacco Survey in India reported 34.6\% of overall tobacco use, $25.9 \%$ smokeless tobacco use and $14.0 \%$ smoking among adults. A nationwide survey has found that smoking is responsible for about one in five deaths in men and one in 20 deaths in women in India. ${ }^{[2]}$ Smoking is more common in rural areas in both men and women. Krishnan et al. reported prevalence of smoking as $41 \%$ and $13 \%$ in men and women respectively in a rural area of Haryana. ${ }^{[3]}$ Government of India enacted the Cigarettes and Other Tobacco Products (Prohibition of Advertisement and Regulation of Trade and Commerce, Production, Supply and Distribution) Act (COTPA) 2003 in May 2003. The act was envisaged to control tobacco use by prohibiting smoking in public places, banning advertisements of the tobacco products, banning sale of tobacco products to minors and near educational institutions, prescribing strong health warnings including pictorial depiction on tobacco products and regulation of tar and nicotine contents of tobacco products. ${ }^{[4]}$ It is essential to study factors affecting the initiation and continuation of tobacco within the community in formulating an intervention to prevent tobacco use. Present study deals with understanding perception 
and practices about tobacco use to provide insight into the problem of tobacco use. It also documents awareness and attitude toward ant-tobacco act in the rural community of north India.

\section{MATERIALS AND METHODS}

Present study was carried out from July 2011 to March 2012 in 28 villages of Ballabgarh block in Haryana. Study area was intensive field practice area of Comprehensive Rural Health Services Project under Centre for Community Medicine, All India Institute of Medical Sciences; New Delhi. ${ }^{[5]}$ Study area included population of almost 90,000 served by two Primary Health Centers. All persons of age more than 15 years, who were residing within the area for past 6 months, were included in the study. Present study was crosssectional, consisted of quantitative and qualitative components. Quantitative survey was done to assess knowledge and attitude about tobacco use. For the quantitative study, villages were taken as clusters. Smaller villages with $<100$ households were clubbed with geographically contiguous villages to form a total of 25 clusters. All clusters were included in the study. Within the cluster, 20 households were selected by systematic random sampling. If there were more than one male and female present in household, one male and one female were selected randomly by lottery method.

Sample size of 880 was estimated by considering prevalence of tobacco use as $30 \%,{ }^{[2]}$ relative precision of $15 \%$, design effect of 2 , and the refusal rate of $10 \%$. Pretested structured interview schedule was used to study perception of tobacco use within the community. Attitude of study participants about various provisions under COTPA was assessed by using five-point likert scale. Likert scale was prepared by using legislatures in the COTPA.

Qualitative study was carried out to understand practices and factors determining tobacco use in the community. It consisted of in-depth interviews and focus group discussion (FGD) Purposive sampling was employed to enroll study participants in the qualitative study. Twenty in-depth interviews and four FGDs were carried out among tobacco users in different age groups and other stakeholders in the community. Stakeholders included health workers, Accredited Social Health Activist, anganwadi workers, members of Panchayati Raj Institution and other opinion leaders in the community. FGD and in-depth interview guide included domains such as age of initiation of tobacco use, types of tobacco form being used and factors determining tobacco use.

\section{Ethical issues}

Ethical clearance for the study was obtained from the Institute Ethics Committee of All India Institute of Medical Sciences, New Delhi.

\section{RESULTS}

A total of 892 subjects were enrolled into the study, of which $51 \%$ were male. Mean age of the study participants was 49.5 years (standard deviation [SD]: 17.5). Mean age of male participants was 50.9 years (SD: 17.8) and while female participants 47.7 years (SD: 17). Other sociodemographic characteristics of the study participants are mentioned in Table 1.

The knowledge within the community about harmful effects of tobacco and legislation regarding tobacco use in the country was classified into appropriate and inappropriate. Though appropriate knowledge about adverse effects of tobacco use was found, awareness regarding legislative measures for tobacco use was inappropriate amongst adults in the community [Table 2]. Attitude of the study participants was supportive toward various provisions under COTPA such as a ban of on tobacco sale to minors, educational premises and advertisement promoting the tobacco products. Study participants were also of view to impose a penalty on smoking in public places and printing health advisory on all tobacco products.

Practices about of tobacco use within the community were assessed by qualitative study in the following domains

\section{Age of initiation of tobacco use}

Tobacco use usually started in teenage. However, in some of the communities like "Raisikh" start using tobacco since childhood.

\begin{tabular}{|c|c|}
\hline Variable & Frequency (\%) \\
\hline \multicolumn{2}{|l|}{ Sex } \\
\hline Male & $455(51)$ \\
\hline Female & $437(49)$ \\
\hline \multicolumn{2}{|l|}{ Age (in years) } \\
\hline $18-24$ & $66(7.4)$ \\
\hline $25-59$ & $509(57.1)$ \\
\hline$\geq 60$ & $317(35.5)$ \\
\hline \multicolumn{2}{|l|}{ Marital status } \\
\hline Currently married & $852(95.5)$ \\
\hline Currently not married & $40(4.5)$ \\
\hline \multicolumn{2}{|l|}{ Caste } \\
\hline Scheduled Castes & $177(19.8)$ \\
\hline Other Backward Castes & $228(25.6)$ \\
\hline Others & $487(55.6)$ \\
\hline \multicolumn{2}{|l|}{ Occupation } \\
\hline Farmer & $217(24.3)$ \\
\hline Semiskilled and unskilled workers & $194(21.7)$ \\
\hline $\begin{array}{l}\text { Government servants, shop owners and } \\
\text { students }\end{array}$ & $70(7.8)$ \\
\hline Housewife & $411(46.1)$ \\
\hline \multicolumn{2}{|l|}{ Education } \\
\hline No education & $407(45.6)$ \\
\hline Primary & $113(12.7)$ \\
\hline Secondary & $272(30.5)$ \\
\hline Higher secondary and above & $100(11.2)$ \\
\hline \multicolumn{2}{|l|}{ Monthly family income (in rupees) } \\
\hline$<2000$ & $140(15.7)$ \\
\hline $2001-4000$ & $446(50.0)$ \\
\hline $4001-6000$ & $194(21.7)$ \\
\hline$>6000$ & $112(12.6)$ \\
\hline
\end{tabular}




\begin{tabular}{|c|c|c|}
\hline \multirow[t]{2}{*}{$\begin{array}{l}\text { Awareness regarding } \\
\text { tobacco use }\end{array}$} & \multicolumn{2}{|c|}{$\begin{array}{l}\text { Assessment of knowledge } \\
\text { regarding tobacco use }\end{array}$} \\
\hline & $\begin{array}{c}\text { Appropriate } \\
\text { knowledge (\%) }\end{array}$ & $\begin{array}{l}\text { Inappropriate } \\
\text { knowledge (\%) }\end{array}$ \\
\hline Tobacco can be injurious to health & $883(99.3)$ & $9(0.7)$ \\
\hline Tobacco can cause cancer & $882(98.9)$ & $10(1.1)$ \\
\hline $\begin{array}{l}\text { Tobacco can cause respiratory } \\
\text { problems }\end{array}$ & $881(98.5)$ & $11(1.5)$ \\
\hline Tobacco can cause a heart attack & $859(96.3)$ & $33(3.7)$ \\
\hline Tobacco can cause stroke & $767(86.0)$ & $125(14.0)$ \\
\hline Tobacco can cause infertility & $537(60.2)$ & $355(39.8)$ \\
\hline All forms of tobacco are harmful & $854(95.7)$ & $38(4.3)$ \\
\hline $\begin{array}{l}\text { Passive smoking is not } \\
\text { dangerous }\end{array}$ & $625(70.1)$ & $267(29.9)$ \\
\hline $\begin{array}{l}\text { Tobacco is not dangerous, if } \\
\text { consumed infrequently }\end{array}$ & $573(64.2)$ & $319(35.8)$ \\
\hline $\begin{array}{l}\text { Professional help is available to } \\
\text { quit tobacco }\end{array}$ & $429(48.1)$ & $463(51.9)$ \\
\hline $\begin{array}{l}\text { Knowledge regarding legislation } \\
\text { to control the use of tobacco }\end{array}$ & $198(22.2)$ & $694(77.8)$ \\
\hline $\begin{array}{l}\text { Age below which tobacco } \\
\text { products cannot be sold }\end{array}$ & $6(0.6)$ & $886(99.4)$ \\
\hline $\begin{array}{l}\text { Distance from educational } \\
\text { institutions in which tobacco } \\
\text { product cannot be sold }\end{array}$ & $166(18.6)$ & $726(81.4)$ \\
\hline $\begin{array}{l}\text { Places where tobacco products } \\
\text { can be advertised }\end{array}$ & $155(17.7)$ & $737(82.3)$ \\
\hline $\begin{array}{l}\text { Penalty for smoking in public } \\
\text { places }\end{array}$ & $0(0)$ & $100(100)$ \\
\hline
\end{tabular}

Early initiation of tobacco use was prevalent irrespective of socioeconomic status in the community.

\section{Types of tobacco forms used in community}

All forms of tobacco such as chewable (guthkha, khaini) and smoking (bidi, cigarette), water-piped smoking (hookah) were consumed in the community. Young population within the community were more inclined toward cigarette smoking and chewing tobacco whereas hookah was preferred by the elderly population. Both smoking bidi and hookah had high social value in the community.

\section{Reasons for initiation of tobacco use}

Major reasons for initiation of tobacco use, as reported by the community members were imitation of elders and peer pressure. Some smokers attributed tobacco use as a way to get relief from abdominal discomfort and stress.

"Prachin samay se chalta aa raha hai, bade bujurg peete hai.

Jaise-jaise bade peete hain, waise waise chote peete hain"

(It is started since a long time. Young ones imitates elders after seeing them using tobacco)
One of the practices told by the study participant was that during social ceremonies such as marriages or other gatherings serving hookah and bidi was a custom. Serving hookah and bidi to the person was believed as a token of respect in the community.

\section{"Hookah nahi puchi humse, bum rishta nabi rakhenge"}

(We will not keep any relationship with you, as they haven't asked us hookah in social gathering).

\section{Continuation of tobacco use}

In spite of knowing the harmful effects, majority perceived no harmful effect of tobacco on their health. Hence, people in the community didn't believe tobacco use as a harmful practice and continue to use it.

'itne saal se pee rahe hain, ab tak. kuch nabi hua to ab kya hoga?'.

(We are using tobacco since a long time and having any harmful effect of it)

Tobacco users and other participants were of view that it was difficult for users to quit because of dependency and withdrawal symptoms. Inadequate knowledge regarding the professional help for quitting tobacco was also reported. Community leaders identified poor implementation of legislation in the villages as reasons of continued use of tobacco in the community.

\section{DISCUSSION}

Present study reported good awareness about harmful effects of tobacco use in a rural community in Ballabgarh block of Haryana. Similar findings were also reported by Raute $e t$ al. in Maharashtra. ${ }^{[6]}$ In this study, participants were distributed across sex, educational and other socioeconomic strata in the community unlike previously reported studies that predominantly consisted of the male population. ${ }^{[7-10]}$ Present study reported poor awareness about various provisions under COTPA. However, supportive attitude was observed toward measures envisaged in the act. Similar findings were reported in the study by Kumar and Misra. ${ }^{[8]}$

The reasons reported for initiation of tobacco use were local custom, peer pressure and imitating elderly in the family. No apparent harmful effect, relief from fatigue and abdominal discomfort were the reasons reported for continuation of tobacco use. Similar findings were reported in other studies from other parts of India. ${ }^{[9,10]}$ Despite of good knowledge about the harmful effects of tobacco use and strong support for antitobacco measures, continued practice of tobacco use was prevalent within the community. This was contradictory to finding reported by Ravishankar and Nagarajappa that poor practice is attributed to inadequate knowledge about tobacco use. ${ }^{[1]}$

Better knowledge about tobacco use observed in this community, might be attributed to social desirability bias. Major strength of the present study was qualitative methodology of the study that was 
a useful tool to understand the complex issue of tobacco use in the community. This study was the first attempt that documented awareness and attitude about COTPA in a rural community in India.

\section{CONCLUSION}

Present study reported the prevalent practices of tobacco use, despite of awareness about harmful effects of tobacco. Tobacco use in this rural community was determined by social customs and values in the community. Poor awareness, but supportive attitude about provisions under COTPA warranted intensive awareness drive about this act in the community. There is a need to address socially accepted practice of hukah and other tobacco products in this community through community participation in the intervention formulation. There is also need to provide professional de-addiction services through existing primary health care services. Comprehensive public health approach is warranted to address this socio-cultural problem of tobacco use in the rural area of north India.

\section{REFERENCES}

1. World Health Organization. WHO Report on the Global Tobacco Epidemic, 2008, The M Power Package. Geneva: World Health Organization; 2008.

2. Jha P, Jacob B, Gajalakshmi V, Gupta PC, Dhingra N, Kumar R, et al. A nationally representative case-control study of smoking and death in India. N Engl J Med 2008;358:1137-47.

3. Krishnan A, Shah B, Lal V, Shukla DK, Paul E, Kapoor SK. Prevalence of risk factors for non-communicable disease in a rural area of Faridabad district of Haryana. Indian J Public Health 2008;52:117-24.

4. Cigarettes and Other Tobacco Products (Prohibition of Advertisement and Regulation of Trade and Commerce, Production, Supply and Distribution)
Act, 2003. Available from: http://www.rctfi.org/Factsheet_on_COTPA.pdf. [Last accessed on 2012 Oct 27].

5. Kant S, Misra P, Gupta S, Goswami K, Krishnan A, Nongkynrih B, et al. The ballabgarh health and demographic surveillance system (CRHSPAlIMS). Int J Epidemiol 2013;42:758-68

6. Raute LJ, Sansone G, Pednekar MS, Fong GT, Gupta PC, Quah AC, et al. Knowledge of health effects and intentions to quit among smokeless tobacco users in India: Findings from the International Tobacco Control Policy Evaluation (ITC) India Pilot Survey. Asian Pac J Cancer Prev 2011;12:1233-8.

7. Jayakrishnan R, Geetha S, Binukumar B, Sreekumar, Lekshmi K. Selfreported tobacco use, knowledge on tobacco legislation and tobacco hazards among adolescents in rural Kerala State. Indian J Dent Res 2011;22:195-9.

8. Kumar R, Misra P. Knowledge, attitude and practices regarding antitobacco measures among members of Panchayati Raj Institutions in a rural area of Haryana. Indian J Public Health 2011;55:339-40.

9. Arora M, Tewari A, Tripathy V, Nazar GP, Juneja NS, Ramakrishnan L, et al. Community-based model for preventing tobacco use among disadvantaged adolescents in urban slums of India. Health Promot Int 2010;25:143-52.

10. Dongre A, Deshmukh P, Murali N, Garg B. Tobacco consumption among adolescents in rural Wardha: Where and how tobacco control should focus its attention? Indian J Cancer 2008;45:100-6.

11. Ravishankar TL, Nagarajappa R. Factors attributing to initiation of tobacco use in adolescent students of Moradabad, (UP) India. Indian J Dent Res 2009;20:346-9.

How to cite this article: Kumar R, Salve H, Misra P. Determinants of tobacco use and perception, attitude about an antitobacco act in rural Haryana, North India. Int J Med Public Health 2014;4:367-70.

Source of Funding support: AlIMS, Intramural research grant, Conflict of Interest: None declared. 